\title{
Advancement of Promoting Developmental Care in Belgium
}

Janssens K, Grevesse L, Clercx A, Claesen M, Haelterman G

Federal Public Services (FPS)

\section{Aims}

The Belgian Federal government promotes Family Centered Developmental Couplet Care nationally. ${ }^{1}$ Since 2012 the Federal Public Services (FPS) has encouraged hospitals to train their medical and nursing staff in developmental care (DC) through educational contracts. Belgian hospitals with such an educational contract are offered financial support and four free DC conference days annually. Moreover, the FPS assigned two DC coordinators to visit these neonatal units. From 2015 till 2017 NICUs training their staff in Newborn Individualized Developmental Care and Assessment Program $\left(\right.$ NIDCAP $^{\circ}$ ) received financial support by the federal government. In June 2017, the FPS began subsidizing DC training, specifically Family Infant Neurodevelopmental Education (FINE) and Compréhension de Langage de L'enfant (CLE) in neonatal units had not didn't receive financial support up to that point.

The objectives of this project are:

- To evaluate the impact of the educational contract on the implementation and evolution of DC practices

- To assess the effect of NIDCAP $^{\bullet}$ professionals working in the neonatal unit on DC practices

\section{Methods}

58 out of 61 hospital sites with an educational contract completed a self-evaluation of their DC practices in the period of 2016-2017. The results of the questionnaire were analyzed in a descriptive manner. A semi-quantitative analysis was then performed for which the institutions received a score on a scale of 1 to 10 regarding a specific item in order to be able to weigh their respective importance on DC practices. The questionnaire comprised five scales: "Environment", "Bed and Sleep", "Care Practices", "Feeding" and "Couplet Care". The sum of the obtained scores from the five scales were calculated with a maximum score of 100. With these figures the NICUs and level II units are able to situate their positions set against the median value.

\section{Results}

NICUs scored significantly higher than level II units on the implementation of DC practices, in all scales but "Feeding" (Environment, $(\mathrm{Z}=2.1804, \mathrm{p}=0.0292)$, Bed and Sleep Practices $(Z=2.0135, p=0.0441)$, Care Practices $(t(49.08)=-5.43$, $\mathrm{p}<0.0001)$, Couplet Care $(\mathrm{Z}=2.0966, \mathrm{p}=0.0360)$ and Total Score $(\mathrm{t}(56)=-3.22, \mathrm{p}=0.0021)$.

Units employing NIDCAP ${ }^{\circledR}$ professionals scored higher. Significant differences were found between teams with and without NIDCAP ${ }^{\oplus}$ professionals (Bed and Sleep $(\mathrm{Z}=2.8321$, $\mathrm{p}=0.0046)$, Care Practices $(\mathrm{t}(56)=2.94, \mathrm{p}=0.0047)$, Feeding $(\mathrm{t}(56)=2.07, \mathrm{p}=0.0426)$, Couplet Care $(\mathrm{Z}=2.1149, \mathrm{p}=.0344$ and Total Score $(\mathrm{t}(56)=3.22, \mathrm{p}=0.0021)$ but not on the "Environment" scale.

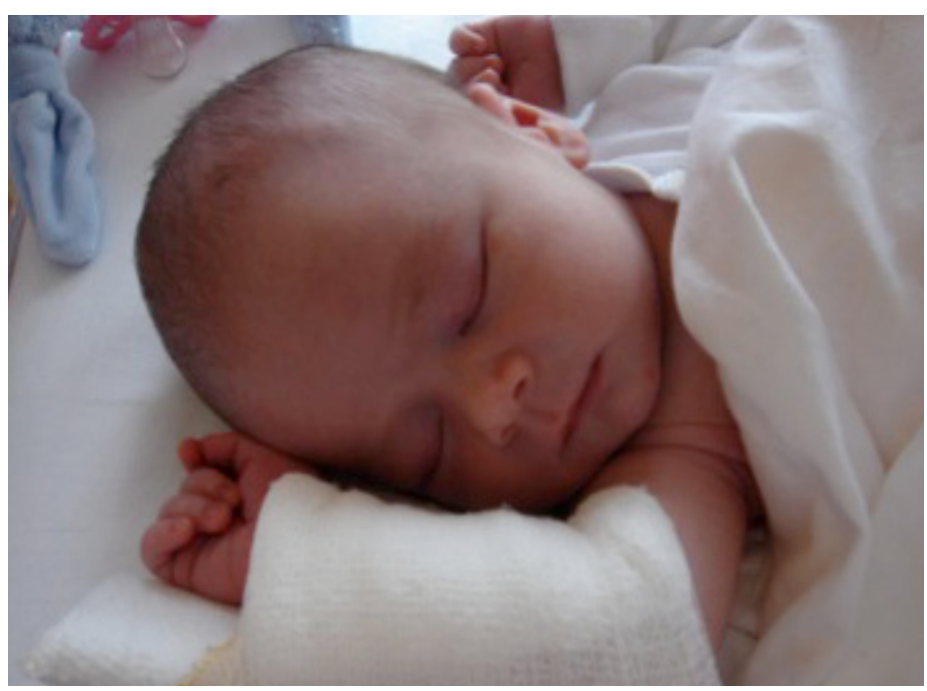

A small but significant correlation $(\mathrm{r}=0,389, \mathrm{p}=0.0019)$ was found for the number of NIDCAP ${ }^{\bullet}$ professionals working in a unit and the scores for DC practices. The more NIDCAP ${ }^{\circ}$ certified personnel working in a unit, the more DC practices were implemented.

Between 2014-2017, in the 35 hospitals that participated every year, a distinctive positive evolution of DC practice was observed. The Total Score average increased with 14 points.

\section{Discussion}

Taking bias into account (self-evaluation, sample size, lack of controls), these results are merely an indication of the invested work in DC within these neonatal units. NICUs apply more DC practices than level II units and the recruitment of NIDCAP ${ }^{\circ}$ professionals resulted in more DC practices. Nevertheless, this project has allowed all the involved units to identify their relative positions within the DC project and use this information to grow. Moreover, based on the quantitative data, the DC project has both illustrated the units' evolution as well as highlighted areas of improvement.

\section{Conclusion}

It is important to continue this project and to incentivize more units to join in or advance DC practices. For a more thorough evaluation of this project, another study is recommended that includes more NIDCAP Professionals and a control site. The creation of a national label in DC will be taken into consideration.

\footnotetext{
References

1. Van Herreweghe I, Druart D, Janssens K, Clercx A, Claesen M, Tackoen M. A Healthcare Policy Aiming to Optimize Parent-Baby Bonding in Hospitals: the Belgian Example Rev. Méd. Périnat. 2016; 8:3:133-40 (In French).
} 